\title{
Failure to block control by a relevant stimulus
}

\author{
VINCENT M. LoLORDO, W. J. JACOBS, and DONALD D. FOREE \\ Dalhousie University, Halifax, Nova Scotia, Canada
}

\begin{abstract}
Pigeons were trained to depress a treadle in the presence of a discriminative stimulus, either a tone or illumination of red houselights, in order to obtain access to grain or avoid electric shock. In avoidance training, the auditory discriminative stimulus yielded faster acquisition than did the visual one. In appetitive training, the visual discriminative stimulus yielded faster acquisition than the auditory one. Experiments 2 and 3 used these stimuli in Kamin's (1969) blocking design. In Experiment 2, when the pigeons were trained to depress a treadle in the presence of tone to obtain grain and then red light was added as the redundant stimulus, the light acquired stimulus control over treadlepressing; blocking was not observed. In Experiment 3, when the pigeons were trained to depress a treadle in the presence of red light to avoid electric shock and then tone was added as the redundant stimulus, the tone acquired stimulus control over treadlepressing. Again, blocking was not observed. The implications of these results for several models of stimulus control are discussed.
\end{abstract}

It has been demonstrated in several paradigms that the experimenter's choice of the reinforcer determines which element of a compound conditioned stimulus or discriminative stimulus will exert the stronger control over responding, that is, there will be a stimulus-reinforcer interaction. One stimulusreinforcer interaction was observed by Foree and LoLordo (1973), who trained groups of pigeons to depress a treadle in the presence of a compound auditoryvisual discriminative stimulus either to avoid electric shock or to obtain grain. After the pigeons were performing well, the individual elements of the compound stimulus, red houselight and a pure tone, were presented separately to assess their control of treadlepressing. In the test, the tone controlled much more responding than did the red houselight in the shock avoidance condition, but the red light controlled more responding than did the tone in the appetitive condition. Thus, the tone was the dominant stimulus in the avoidance condition, but the red light was the dominant stimulus in the appetitive condition.

Kamin (1969) found that, for rats in a conditioned emotional response (CER) procedure, the occurrence of stimulus dominance following compound training could be predicted on the basis of the rates of acquisition in independent groups conditioned to the separate elements. One group of rats conditioned rapidly

This research was supported by Grant A-9585 from the Natural Sciences and Engineering Research Council of Canada and by grants from Dalhousie University to V.M.L. and D.D.F. We would like to thank Janet Lord and Linda Baril for technical assistance, R. S. Rodger and Franklin Goodkin for advice on statistical matters, and Alan Randich, Kimron Shapiro, Peter Urcuioli, and Jeffrey Willner for critical comments on an earlier version of the manuscript. Requests for reprints should be sent to Vincent $M$. LoLordo, Department of Psychology, Dalhousie University, Halifax, Nova Scotia B3H 4J1, Canada. to illumination of an overhead light, and another group conditioned slowly to a $50-\mathrm{dB}$ noise. When a third group was conditioned from the outset with a light-noise compound CS, the light was the dominant stimulus.

Kamin's account of these data also implies that the relative rates of acquisition in groups conditioned with separate elements could be predicted on the basis of the direction of dominance in a test following training with a compound of those elements. Although this prediction was borne out in Kamin's preparation, it need not be correct in other conditioning and training situations. For example, stimulus dominance might be the result of selective attention or any other process that emerges only in compound conditioning situations, and thus might have no implications for rates of conditioning in groups given separate elements.

Experiment 1 investigated whether the same stimulus-reinforcer interaction observed by Foree and LoLordo would also occur when rates of acquisition of discriminated treadlepressing by independent groups of pigeons receiving training with the separate elements were compared. That is, when no process which emerges only in compound conditioning can be operating, will acquisition of shock avoidance responding occur more rapidly with an auditory discriminative stimulus than with a visual one, and will acquisition of food-reinforced responding occur more rapidly with a visual stimulus than with an auditory one?

\section{EXPERIMENT 1}

\author{
Method \\ Subjects. The subjects were 32 adult male white Carneaux \\ pigeons, randomly assigned to four equal-sized groups. Each bird
}


was maintained at $80 \%$ of its free-feeding weight, and was implanted with stainless steel pubis electrodes attached to a leather harness worn at all times (Azrin, 1959; Coughlin, 1970).

Apparatus. The experimental chamber was a $30 \times 30 \times 30 \mathrm{~cm}$ ventilated sound-attenuating chamber with two opposing white wooden walls and two removable, aluminum walls. A $15 \times 20 \mathrm{~cm}$ covered observation window was centered in one wooden wall. A Bakelite bar, with a $9 \times 7 \mathrm{~cm}$ Masonite treadle attached, extended through a rectangular hole in the center of one aluminum wall. The treadle was tilted down from the wall at a $30-\mathrm{deg}$ angle to the floor. In its rest position, the lower edge of the treadle was $3.5 \mathrm{~cm}$ from the hardware cloth floor. A downward force of $.49 \mathrm{~N}$ on the treadle activated a microswitch, defining a response. Grain could be presented through a $5 \times 4.5 \mathrm{~cm}$ opening to the left of the treadle on the same wall. The ceiling consisted of a piece of translucent white Plexiglas. Two 7.5-W white lights, a 7.5-W and a 40-W red light, and a Utah SP25A loudspeaker were mounted above the ceiling.

To provide electric shock, $60-\mathrm{Hz} 110-\mathrm{V}$ ac passed through a variable transformer and then through a $10-\mathrm{k} Q$ resistor. Shock was transmitted via a cable connected at one end to a swivel in the ceiling of the chamber and at the other end to a banana plug that was plugged into the socket on the bird's harness immediately prior to each session. Continuous masking noise at $70 \mathrm{~dB}$ (SPL) was provided by the chamber ventilation fan and white noise in the experimental room.

Procedure. Each pigeon was assigned to one of four groups. Two of these groups received an appetitive instrumental training procedure, and two received a shock avoidance procedure. At the beginning of each 1 -h session, the banana plug connected to the swivel in the ceiling of the chamber was plugged into the socket on the bird's harness, even though birds in the appetitive group received no shock.

In appetitive training, the birds were permitted to eat from the grain magazine in the presence of the stimulus that was to be the discriminative stimulus in subsequent treadlepress training. This stimulus was a $440-\mathrm{Hz}$ tone that increased the sound level from 70 to $76 \mathrm{~dB}$ (SPL) for one group of pigeons and the illumination of the red houselights for a second group. The grain magazine was repeatedly elevated until the pigeon reliably approached and ate within a few seconds of its elevation. Then, in the presence of the stimulus that was later used as the discriminative stimulus, 5 -sec periods of access to grain were presented on a responseindependent, variable-time 1 -min schedule for the rest of the session. In the following sessions, training of the treadlepress response occurred. The training schedule included a $20-\mathrm{sec}$ intertrial period during which white houselights were illuminated and no tone was on. Depression of the treadle during this period extended the intertrial interval for $20 \mathrm{sec}$ from the time of the response. When no treadlepress response occurred for $20 \mathrm{sec}$, a 20 -sec trial period began. During the trial, the discriminative stimulus was present. The discriminative stimulus was the $440-\mathrm{Hz}$ tone for one group and illumination of red houselights (and extinction of white houselights) for the other. A response during the trial terminated the discriminative stimulus and produced 5 -sec access to grain, followed by reinstatement of the intertrial conditions. Whenever grain was available, the grain magazine was illuminated with white light, but the pigeon was otherwise in darkness. If $20 \mathrm{sec}$ elapsed without a treadlepress response in the presence of the discriminative stimulus, the stimulus was terminated and the intertrial conditions were reinstated.

Although Foree and LoLordo used a 15 -sec intertrial period and a 5 -sec trial period, 20 -sec intervals were used in this experiment. We wanted to avoid biases in acquisition rates that would result from shaping the birds' treadlepress response by the method of successive approximation, and believed that in the absence of shaping, the birds might not acquire the response unless the trial period was lengthened. Each bird was trained to a criterion that included: (1) receipt of at least 80 trials in a given session, that is, a low rate of intertrial responding, and (2) emission of a response on at least $75 \%$ of the trials in that session.
In the first session of avoidance training, the pigeons were placed on an avoidance schedule designed to match the appetitive schedule described above. Each response in the intertrial condition (white houselights, no tone) extended the intertrial interval by $20 \mathrm{sec}$ from the time of the response. After $20 \mathrm{sec}$ had elapsed without a treadlepress response in the intertrial condition, the discriminative stimulus was presented. The discriminative stimulus was the tone for one group of pigeons and illumination of the red houselights for the other. A treadlepress response in the presence of the discriminative stimulus reinstated the intertrial conditions and prevented the occurrence of shock. If $20 \mathrm{sec}$ elapsed without a response in the presence of the discriminative stimulus, a brief electric shock was presented. Shocks were presented every $20 \mathrm{sec}$ in the presence of the discriminative stimulus until a response was made. The shock voltage was increased from 30 to $72 \mathrm{~V}$ in steps of $6 \mathrm{~V}$ per session for all birds. The birds were run to an acquisition criterion like that required of birds in the appetitive condition: (1) receipt of at least 80 trials in a given session and (2) emission of a response prior to shock on at least $75 \%$ of those trials.

\section{Results}

The dependent variable of most interest was the number of sessions required for pigeons in each group to attain the acquisition criterion. The left panel of Figure 1 illustrates the data from the groups of birds that received food reinforcement. The data points represent the number of days to criterion required by individual birds, and the heights of the bars repre-

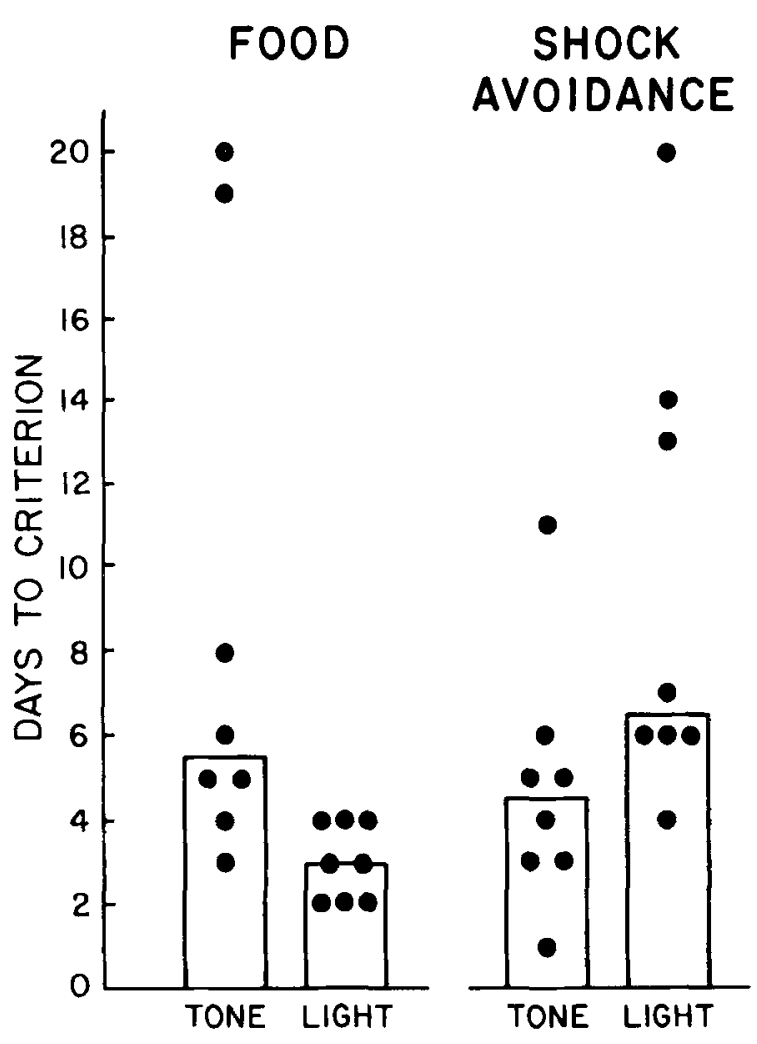

Figure 1. Median number of sessions to the acquisition criterion for groups of birds that received either tone or light as the discriminative stimulus for treadlepressing to obtain food (left panel) or to avoid shock (right panel). Filled circles are data points for individual birds. 
sent the group medians. The group that received the visual discriminative stimulus acquired the discriminated treadlepress response faster than the group that received the auditory discriminative stimulus (Mann-Whitney $U=3, p<.05$ ).

The right panel of Figure 1 illustrates the data of the groups of birds that received avoidance training. The group that received the auditory discriminative stimulus acquired the discriminated treadlepress response significantly faster than the group that received the visual discriminative stimulus $(U=12$, $\mathrm{p}<.05)$.

\section{Discussion}

In avoidance training, the auditory discriminative stimulus yielded faster acquisition than the visual one, whereas in appetitive training the visual discriminative stimulus yielded faster acquisition than the auditory one. Given the stimulus-reinforcer interaction observed following compound conditioning by Foree and LoLordo, the present pattern of data is in accord with Kamin's account of stimulus dominance in compound conditioning. Thus, the observed stimulus-reinforcer interaction does not depend primarily upon some subtle, emergent effect of compound stimulus training.

\section{EXPERIMENT 2}

Kamin (1969) also demonstrated that prior conditioning to one stimulus may prevent conditioning to a second, added stimulus. He exposed one group of rats to repeated presentations of a visual conditioned stimulus (CS) followed immediately by electric shock in a CER procedure (Estes \& Skinner, 1941), while a control group received no treatment. Both groups then received presentations of a compound CS, consisting of white noise and the previously conditioned visual stimulus, followed immediately by electric shock. When the white noise subsequently was presented alone, it produced virtually complete suppression of food-reinforced leverpressing in the controls, but had little effect upon the response rate of rats in the experimental group. Kamin suggested that prior conditioning to the light "blocked" the conditioning of suppression to the redundant noise in the experimental group.

Blocking has been demonstrated in a wide variety of procedures, including Pavlovian excitatory conditioning of the rabbit's nictitating membrane response (Marchant \& Moore, 1973), Pavlovian inhibitory conditioning of the rat's CER (Suiter \& LoLordo, 1971), food-reinforced, discriminated operant conditioning of pigeons (e.g., Chase, 1968; Johnson, 1970; Mackintosh \& Honig, 1970; Miles, 1970; vom Saal \& Jenkins, 1970), rats (e.g., Seraganian \& vom Saal, 1969), and fish (Tennant \& Bitterman, 1975), formation of conditioned taste aversions in rats (Gillan \&
Domjan, 1977; Willner, 1978), and concept identification training of college students (Trabasso \& Bower, 1968).

Few experiments on blocking have used two stimuli which are known to yield a stimulus-reinforcer interaction in either the single-cue or the compoundcue design. Such stimulus-reinforcer interactions have been thought to reflect the biological relevance of each stimulus for one of the reinforcers; that is, that one stimulus is especially easily associated with one of the reinforcers, and the other, with the other reinforcer (e.g., Capretta, 1961; LoLordo, 1979; Seligman, 1970; Shettleworth, 1972, 1979).

Some investigators have suggested that the laws of learning are different for relevant stimuli and other cues. If this is so, then the outcomes of standard stimulus control paradigms should be atypical when relevant stimuli are used.

Suppose that when one of the stimuli used in our experiments precedes the reinforcer for which it is relevant, it cannot be ignored. In such a case, when the relevant stimulus is added to an already conditioned stimulus, it should be relatively impervious to blocking. Experiments 2 and 3 ask whether control by a relevant discriminative stimulus is blocked by prior conditioning with another, less relevant, discriminative stimulus. Specifically, when pigeons are trained to depress a treadle in the presence of a tone to obtain food, and then red light is added as a redundant stimulus, will the light acquire control over treadlepressing? Conversely, when pigeons are trained to depress a treadle in the presence of red light to avoid shock, and then tone is added as a redundant stimulus, will the tone acquire control over treadlepressing? Experiment 2 asked the first of these questions; Experiment 3 asked the second.

\section{Method \\ Subjects. The subjects were 24 experimentally naive White King pigeons. The birds were housed in individual cages and had free access to grit and water at all times. Although no electric shock was used in the present experiment, on the day prior to the first experimental session, each bird was implanted with stainless steel wire electrodes around the pubis bones. The electrodes were con- nected to a double banana socket attached to a leather harness worn by the birds at all times. All birds were maintained at $80 \%$ free-feeding weight and were on an 18-h-light/6-h-dark cycle for the duration of the experiment.}

Apparatus. The apparatus of Experiment 1 was also used in Experiment 2.

Design and Procedure. The pigeons were randomly assigned to four groups of six birds each. The design of the experiment included three phases that are common to experiments on blocking. In the first phase, birds in Groups TT, TC, and TL were trained to respond in the presence of tone to produce food, while birds in Group $\mathrm{CC}$ were trained to respond in the presence of a compound of tone and red light.

In the second phase, the schedule of reinforcement was unchanged, and red light was added to tone for the blocking group, Group TC. That is, birds in this group received the compound discriminative stimulus during this phase. Red light was substituted for tone for Group TL, whereas Group TT continued to receive the auditory stimulus and Group $\mathrm{CC}$, the compound stimulus. 
In the third, or test, phase, all groups received presentations of the compound stimulus, the red light alone, and the tone alone.

Comparison of test responding to light in Groups TC and TL would reveal whether there was any interference with conditioning to the relevant light during compound training as a result of either prior conditioning to the less relevant tone or overshadowing of light by tone during compound training. Fewer test responses to the light in Group TC than in Group TL would indicate that either blocking or overshadowing (or both) was operating. Given such a difference, equal test responding to hight in Groups TC and $\mathrm{CC}$ would reveal that overshadowing was operating, whereas more test responding to light in Group CC than in Group TC would indicate that blocking was operating. Comparison of test responding to the light in Groups TC and TT would indicate whether blocking was complete. TT is an appropriate control for generalized responding to the light during the test session, as well as for acquisition of responding to the light during the test session.

All sessions were run daily for $1 \mathrm{~h}$ each day. Initially, birds were trained to eat from the food hopper in the presence of: (1) a $440-\mathrm{Hz}$ tone that increased the sound level from 70 to $76 \mathrm{~dB}$ (SPL) (Groups TT, TL, TC), or (2) a compound of the tone and illumination of the 7.5- and 40-W red houselights (Group CC). Following magazine training, the birds were shaped to depress the treadle on a continuous reinforcement schedule for $5-\mathrm{sec}$ access to grain. During shaping, an intertrial stimulus consisting of illumination of the two 7.5-W white houselights and the absence of tone followed each reinforcement for $.5 \mathrm{sec}$. When treadlepressing was established, the duration of the intertrial interval was lengthened to $15 \mathrm{sec}$ and the duration of the trial, that is, tone ( $T$ ) or compound (C) stimulus, was reduced to $5 \mathrm{sec}$ over a period of 3-30 days. If a bird's performance deteriorated, the duration of the trial stimulus was increased until performance improved and then trial duration was decreased again. Each response in the intertrial interval reset the interval and caused a brief $(160 \mathrm{msec})$ darkening of the chamber.

The final training schedule in Phase 1 consisted of an intertrial interval of at least $15 \mathrm{sec}$, during which the white houselights and no tone were on. Each response in the intertrial interval extended the interval for $15 \mathrm{sec}$ from the time of the response. A 5 -sec trial period began at the end of the intertrial interval. During the trial, Groups TT, TL, and TC received a tone, whereas Group CC received a compound of red light and tone. In the presence of the discriminative stimulus, the first treadlepress response produced 5 -sec access to an illuminated, grain-filled magazine and terminated the tone and all houselights. Following reinforcement, or after $5 \mathrm{sec}$ in the presence of the discriminative stimulus, the intertrial stimuli were reinstated. The birds were run under their respective stimulus conditions until they met criterion by responding on at least $75 \%$ of the trials in a session. An additional five sessions were then run under identical stimulus conditions.

Phase 2 consisted of five additional sessions, which differed from the last sessions of Phase 1 only in the discriminative stimuli that were presented to the various groups. Groups TC and CC received the compound stimulus, Group $\mathrm{TL}$, the red light stimulus, and Group TT, the auditory stimulus.

On the day following the completion of Phase 2, the birds were tested for stimulus control. The test included a 15-min warm-up period, during which the stimuli of Phase 2 were used. Then 60 test trials consisting of 20 presentations each of the compound stimulus and its elements (red light alone or tone alone) were presented randomly. Responses to the compound stimulus and either of its elements were reinforced throughout the test.

Overall analyses of variance were carried out, and the $F$ values were compared with Rodger's (1975) tables of F[E $\alpha] ; v_{1}, v_{2}$. In each analysis in which the overall null hypothesis was rejected, a set of mutually orthogonal post hoc contrasts of the form $\Sigma_{j} c_{j} m_{j}$, where $\Sigma_{j} c_{j}=0$ and $m_{j}$ are sample means, were sought. Such a set of contrasts are comparisons of weighted combinations of the means in which the coefficient $c_{j}$ is the weight given to the $j^{\text {th }}$ mean $\mathrm{m}_{\mathbf{j}}$. The critical value for rejecting each null contrast was obtained from Rodger (1975). The F[.05]; $v_{1}, v_{2}$ used in these analyses insured that the proportion of null contrasts rejected in error would be $\alpha=.05$ when all null contrasts were true.

\section{Results}

Phases 1 and 2. Table 1 presents, for each of the four groups, the mean number of trials received and the mean percentage of trials on which a response occurred for each of the last 5 days of Phase 1 (called Days 1-5 of Phase 1 in the description of the results) and the 5 days of Phase 2. The percentage of trials on which a response occurred was the primary measure of performance. However, since responses that occurred between trials delayed the occurrence of the next trial, the number of trials per session was considered an appropriate supplementary measure of discriminative performance. This measure is sensitive to variation in the number of widely spaced intertrial responses but insensitive to variations in the number of bursts of responses, for example, at the termination of a trial.

On the 3rd and 5th (last) days of Phase 1, the three groups that received the auditory discriminative stimulus performed similarly, and all received fewer trials than Group CC. Furthermore, on Day 1 of Phase 2, Group CC again received more trials than any of the other groups. These, and the following conclusions, are supported by the results of ANOVAs.

Generally, discriminative performance appeared to be asymptotic at the end of Phase 1 , although Group TT showed considerable day-to-day variability in the percentage of trials on which a response occurred, whereas Group TL showed significant dayto-day variability in the number of trials received. In neither case did the data reveal a consistent trend.

On the first day of Phase 2 , the discriminative stimulus was changed for Groups TL and TC. The change from an auditory to a visual discriminative stimulus disrupted the discriminative responding of

Table 1

Mean Number of Trials Received and Mean Percentage of Trials on Which a Response Occurred on Each of the Last 5 Days of Phase 1 and on Each Day of Phase 2 for the Various Groups of Experiment 2

\begin{tabular}{|c|c|c|c|c|c|c|c|c|c|c|}
\hline \multirow[b]{2}{*}{ Group } & \multicolumn{5}{|c|}{ Phase 1} & \multicolumn{5}{|c|}{ Phase 2} \\
\hline & Day 1 & Day 2 & Day 3 & Day 4 & Day 5 & Day 1 & Day 2 & Day 3 & Day 4 & Day 5 \\
\hline $\mathrm{TC}$ & $126 / 78$ & $132 / 73$ & $139 / 64$ & $134 / 75$ & $135 / 78$ & $132 / 67$ & $138 / 68$ & $144 / 62$ & $153 / 67$ & $148 / 56$ \\
\hline TT & $145 / 71$ & $138 / 74$ & $149 / 65$ & $137 / 83$ & $143 / 56$ & $136 / 72$ & $132 / 90$ & $133 / 82$ & $135 / 65$ & $132 / 71$ \\
\hline TL & $135 / 69$ & $132 / 74$ & $128 / 87$ & $143 / 81$ & $134 / 86$ & $134 / 51$ & $136 / 81$ & $142 / 76$ & $147 / 85$ & $153 / 84$ \\
\hline $\mathrm{CC}$ & $156 / 82$ & $149 / 72$ & $159 / 68$ & $153 / 81$ & $158 / 79$ & $158 / 79$ & $152 / 82$ & $151 / 73$ & $151 / 72$ & $154 / 76$ \\
\hline
\end{tabular}


Group TL for one session, during which the percentage of trials on which a response occurred declined markedly. There was no effect on responding in Group TC when red light was added to tone.

Testing. Table 2 illustrates the number of test responses to the compound stimulus and to each of its elements for individual birds in each group. A maximum of 20 responses to each stimulus was possible. Separate ANOVAs were run for number of responses to each stimulus. Analysis of test responding to the compound revealed no significant difference among groups.

Analysis of test responding to the light revealed significant between-groups differences $[F(3,20)=$ 4.58]. Further analyses revealed no differences in response to the light among Groups TC, TL, and CC. Group TT made significantly fewer responses to light than did these three groups $(F=3.86)$. Thus, there is no evidence of blocking of visual control as a result of prior conditioning to the tone: Groups TC and TL did not differ. Furthermore, test responding to the light in Group TC cannot be explained solely in terms of stimulus generalization from tone to light during the test, or in terms of acquisition of responding to the light during the test, since Group TT made significantly fewer responses to light than did Group TC.

Analysis of test responding to the tone revealed significant between-groups differences $[F(3,20)=$ 3.80]. Groups TC and TT did not differ significantly from each other, but both responded significantly more often to the tone than did Group $\mathrm{CC}(\mathrm{F}=3.59)$. The greater test responding to tone in Group TT than in Group CC indicates that the tone was overshadowed by the light during compound training. Responding in Group TL did not differ significantly from the average responding of Groups TT, TC, and CC. This decision set implies (Rodger, 1974, 1975) that the populations are ordered on mean test responding to tone as follows, with the most responsive groups on the right:

$$
\begin{array}{r}
\mathrm{CC}<\mathrm{TL}<\mathrm{TC} \\
\mathrm{TT}
\end{array}
$$

The equal test responding to tone in Groups TC and
TT suggests that the tone did not lose control of responding during compound training of Group TC.

\section{Discussion}

The data bearing most directly on the question that engendered this experiment, namely, whether conditioning to a relevant, added visual stimulus (Foree and LoLordo, 1973) would be blocked by prior conditioning to a less relevant, auditory stimulus, come from the test responding of Groups TC, TL, and TT. Test responding to the light revealed no difference between Groups TC and TL, suggesting that light acquired as much associative strength during compound training of Group TC as it did during light training of Group TL, when no tone was present. Thus there is no evidence of blocking. Furthermore, since Group TT responded less frequently to light than did Groups TC and TL, test responding to light in the latter groups was in large part acquired during Phase 2, although stimulus generalization of the effects of reinforced responding to tone, or acquisition of responding to light during the test, or both, apparently occurred as well. Groups TC and TT responded equally often to the tone during the test, and both responded more often than did Group TL. Thus, while the light was acquiring considerable associative strength during compound training of Group TC, concurrently the tone was maintaining its associative strength as well as it did when it was the only stimulus present (i.e., during Phase 2 of training in Group TT).

Group TT responded more frequently to test presentations of the tone than did Group CC, suggesting that tone was overshadowed by light during compound training despite 10 days of overtraining to the compound. This outcome is in accord with the description, based on Experiment 1 and the studies of Foree and LoLordo $(1973,1975)$, of the light as a relevant stimulus, and the tone as a less relevant stimulus, in appetitive training of pigeons.

The results of Experiment 2 suggest that control by a relevant stimulus is not blocked by prior conditioning to a less relevant stimulus. Since tone becomes the more relevant stimulus when the reinforcer is changed from food to shock avoidance, perhaps

Table 2

\begin{tabular}{|c|c|c|c|c|c|c|c|c|c|c|c|c|c|c|c|}
\hline \multicolumn{4}{|c|}{ Group TC } & \multicolumn{4}{|c|}{ Group TL } & \multicolumn{4}{|c|}{ Group TT } & \multicolumn{4}{|c|}{ Group CC } \\
\hline Bird & C & $\mathrm{T}$ & L & Bird & $\mathrm{C}$ & $\mathrm{T}$ & L & Bird & $\mathrm{C}$ & $\mathrm{T}$ & $\mathrm{L}$ & Bird & $\mathrm{C}$ & $T$ & L \\
\hline 8087 & 19 & 12 & 16 & 9408 & 16 & 6 & 15 & 9407 & 4 & 10 & 5 & 8407 & 13 & 4 & 16 \\
\hline 8111 & 20 & 20 & 17 & 9028 & 13 & 0 & 13 & 9372 & 20 & 20 & 20 & 9523 & 17 & 0 & 6 \\
\hline 8134 & 8 & 14 & 11 & 9814 & 18 & 20 & 20 & 8716 & 18 & 20 & 4 & 7817 & 13 & 0 & 8 \\
\hline 9683 & 20 & 19 & 20 & 8426 & 20 & 18 & 19 & 9451 & 20 & 18 & 5 & 9104 & 20 & 19 & 20 \\
\hline 9080 & 9 & 5 & 11 & 8174 & 17 & 13 & 18 & 0099 & 10 & 14 & 8 & 8309 & 17 & 6 & 16 \\
\hline 9889 & 20 & 17 & 19 & 8526 & 17 & 6 & 17 & 9626 & 5 & 16 & 10 & 8769 & 19 & 1 & 19 \\
\hline
\end{tabular}

Number of Test Responses to Compound (C), Tone (T), and Red Light (L) for Individual Birds in Experiment 2 
in the avoidance situation conditioning of a treadlepress response to the less relevant light stimulus will fail to block conditioning of the response to an added, relevant tone. Experiment 3 investigated this possibility.

\section{EXPERIMENT 3}

\section{Method}

Subjects. Twenty-four experimentally naive White King pigeons served as subjects. The birds were housed, maintained, and fitted with harnesses and electrodes as in Experiment 2.

Apparatus. The apparatus of Experiment 1 was also used in Experiment 3.

Design and Procedure. The design of this experiment was identical to that of Experiment 2, except that the roles of tone and red light were interchanged. In the first phase of the experiment, Groups LC, LT, and LL received the red light stimulus, whereas Group $\mathrm{CC}$ received the compound stimulus. In the second phase, Groups LC and CC received the compound stimulus, Group LT, the tone, and Group LL, the red light. In the third phase, all groups received presentations of the compound, the red light alone, and the tone alone.

Comparison of test responding to tone in Groups LC and LT reveals whether there was any interference with conditioning to the relevant tone during compound training as a result of either prior conditioning to the less relevant light or overshadowing of tone by light during compound training. Fewer test responses to the tone in Group LC than in Group LT would indicate that blocking or overshadowing, or both, was operating. Given such a difference, equal test responding to tone in Groups $\mathrm{LC}$ and $\mathrm{CC}$ would reveal that overshadowing was operating, whereas more test responding to tone in Group $\mathrm{CC}$ than in Group LC would indicate that blocking was operating. Comparison of test responding to the tone in Groups LC and LL indicates whether blocking was complete. LL is an appropriate control for generalized responding to the tone during the test session, as well as for acquisition of responding to the tone during that session.

In the first session, the birds were placed on the avoidance schedule. Each response in the intertrial condition (white houselights, no tone) extended the intertrial interval by $15 \mathrm{sec}$ from the time of the response. After $15 \mathrm{sec}$ had elapsed without a treadlepress response in the intertrial condition, the discriminative stimulus was presented. In Phase 1 of the experiment, the discriminative stimulus was illumination of the red houselights for Groups LC, LT, and LL, and a compound of the red houselights and the tone for Group CC. A leverpress in the presence of the discriminative stimulus reinstated the intertrial conditions and prevented the occurrence of shock. If $5 \mathrm{sec}$ elapsed without a response in the presence of the discriminative stimulus, a brief electric shock was presented. Shocks were presented every $5 \mathrm{sec}$ in the presence of the discriminative stimulus until a response was made. The shock voltage was scheduled to be increased from 30 to $70 \mathrm{~V}$ in steps of $5 \mathrm{~V}$ per session. The birds were run under their respective stimulus conditions until they met criterion by responding prior to the first shock on at least $75 \%$ of the trials in a session. An additional five sessions were then run under identical stimulus conditions.

Phase 2 consisted of five additional sessions, which differed from the last sessions of Phase 1 only in the discriminative stimuli that were presented to the various groups. Groups LC and CC received the compound stimulus, Group LT, the auditory stimulus, and Group LL, the red light. If a bird reached the acquisition criterion before the shock intensity reached $70 \mathrm{~V}$, then shock intensity was not increased further.

The birds were tested for stimulus control on the day after the completion of Phase 2. The test included a 15-min warm-up period during which the stimuli of Phase 2 were used. Then 60 test trials, consisting of 20 presentations each of the compound stimulus and its elements (red light alone or tone alone), were randomly presented. Responses to the compound stimulus and either of its elements were reinforced throughout the test. If no response occurred on a test trial, the intertrial conditions were reinstated after the first shock, and no further shocks were presented on that trial.

\section{Results}

Phases 1 and 2. Table 3 presents, for each of the four groups, the mean number of trials received and the mean percentage of trials on which an avoidance response occurred for each of the last 5 days of Phase 1 and the 5 days of Phase 2. The table suggests the following conclusions, which are supported by the results of ANOVAs.

First, responding to the red light appeared to be asymptotic during the last 5 days of Phase 1. For the three groups that received red light during that phase (Groups LC, LT, and LL combined), there was no trend in the percentage of trials on which an avoidance response occurred or in the number of trials received. Moreover, neither the number of trials received nor the percent avoidances differed in the two phases for Group LL, which received red light in both.

On the 1st day of Phase 2, the discriminative stimulus was changed for Groups LT and LC. For Group LT, the switch disrupted discriminative responding for one session on both measures and for a second session in terms of the number of trials received. There was no disruption of performance when tone was added to red light for Group LC. Indeed, the number of trials per session received by birds in this group increased with the addition of the tone.

Testing. Table 4 illustrates the number of test responses to the compound stimulus and to each of its elements for individual birds in each group. A max-

Table 3

Mean Number of Trials Received and Mean Percentage of Trials on Which a Response Occurred on Each of the Last 5 Days of Phase 1 and on Each Day of Phase 2 for the Various Groups of Experiment 3

\begin{tabular}{|c|c|c|c|c|c|c|c|c|c|c|}
\hline \multirow[b]{2}{*}{ Group } & \multicolumn{5}{|c|}{ Phase 1} & \multicolumn{5}{|c|}{ Phase 2} \\
\hline & Day 1 & Day 2 & Day 3 & Day 4 & Day 5 & Day 1 & Day 2 & Day 3 & Day 4 & Day 5 \\
\hline LC & $125 / 67$ & $140 / 71$ & $142 / 82$ & $138 / 77$ & $127 / 74$ & $148 / 86$ & $158 / 84$ & $151 / 84$ & $163 / 87$ & $152 / 89$ \\
\hline LL & $121 / 84$ & $139 / 87$ & $142 / 90$ & $138 / 89$ & $141 / 90$ & $143 / 92$ & $148 / 94$ & $150 / 89$ & $153 / 92$ & $145 / 91$ \\
\hline $\mathrm{LT}$ & $147 / 80$ & $156 / 90$ & $158 / 90$ & $149 / 91$ & $156 / 93$ & $95 / 64$ & $134 / 90$ & $156 / 92$ & $162 / 95$ & $167 / 94$ \\
\hline $\mathrm{CC}$ & $110 / 82$ & $133 / 81$ & $128 / 77$ & $127 / 83$ & $147 / 86$ & $144 / 89$ & $141 / 88$ & $151 / 90$ & $158 / 89$ & $156 / 91$ \\
\hline
\end{tabular}


Table 4

Number of Test Responses to Compound (C), Tone (T), and Red Light (L) for Individual Birds in Experiment 3

\begin{tabular}{|c|c|c|c|c|c|c|c|c|c|c|c|c|c|c|c|}
\hline \multicolumn{4}{|c|}{ Group LC } & \multicolumn{4}{|c|}{ Group LT } & \multicolumn{4}{|c|}{ Group LL } & \multicolumn{4}{|c|}{ Group CC } \\
\hline Bird & $\mathrm{C}$ & $\mathbf{T}$ & $\mathbf{L}$ & Bird & C & $\mathbf{T}$ & $\mathbf{L}$ & Bird & $\mathrm{C}$ & $\mathrm{T}$ & $\mathrm{L}$ & Bird & C & $T$ & L \\
\hline 5092 & 20 & 20 & 20 & 7179 & 19 & 20 & 18 & 0245 & 20 & 11 & 18 & 7564 & 19 & 16 & 3 \\
\hline 7501 & 20 & 15 & 15 & 7632 & 20 & 20 & 20 & 7857 & 17 & 12 & 19 & 0039 & 18 & 12 & 6 \\
\hline 2647 & 20 & 19 & 20 & 0016 & 19 & 19 & 17 & 6031 & 19 & 12 & 20 & 7300 & 19 & 20 & 16 \\
\hline 9646 & 19 & 16 & 13 & 0663 & 20 & 20 & 20 & 0003 & 20 & 13 & 19 & 0004 & 20 & 18 & 18 \\
\hline 5105 & 8 & 8 & 4 & 0012 & 20 & 20 & 20 & 0010 & 20 & 19 & 20 & 0016 & 20 & 17 & 9 \\
\hline 5085 & 8 & 3 & 1 & 0006 & 19 & 20 & 18 & 0030 & 19 & 11 & 19 & 6000 & 20 & 19 & 15 \\
\hline
\end{tabular}

Note-The maximum possible number of responses is 20 .

imum of 20 responses to each stimulus was possible. All of the birds except two in Group LC responded well to the compound stimulus. However, Birds 5105 and 5085 responded infrequently on compound trials, even though these birds had been responding on $89 \%$ and $73 \%$ of the compound training trials on the previous day. We judged the performance of these birds to be so atypical as to justify either of two approaches to the data. First, we could simply discard the data from these birds, and analyze the raw data from the remaining birds. Second, we could express responding in the presence of each stimulus element as a proportion of responding to the compound, thus taking into account differences in the tendency to respond during the test session. These two approaches will be presented in turn.

First, separate ANOVAs for unequal Ns (excluding Birds 5085 and 5105) were run for number of responses to each stimulus. Obtained $F$ values were compared with standard F tables $(\alpha=.05)$.

Analysis of test responding to the compound revealed no significant difference among groups. Analysis of test responding to tone, on the other hand, revealed significant between-groups differences $[F(3,18)=8.32]$. Subsequently, a series of $t$ tests revealed no significant differences among Groups LC, LT, and CC. Another $t$ test revealed that Group LC responded significantly more often to tone than did Group LL $[t(8)=2.48]$. Thus there is no evidence of blocking of auditory control as a result of prior conditioning to the red light; Groups LC and LT did not differ. Moreover, test responding to the tone in Group LC cannot be explained in terms of stimulus generalization from light to tone during the test, or in terms of acquisition of responding to the tone during the test, since Group LL made significantly fewer responses to tone than Group LC.

Analysis of test responding to the red light revealed significant between-groups differences $[F(3,18)=$ 6.37]. Subsequently, a series of $t$ tests revealed no significant differences among Groups LC, LL, and LT. Group LL responded significantly more often to the red light than did Group CC $[\mathrm{t}(10)=3.22]$, indicating that the light was overshadowed by the tone during compound training.
In our second analysis, which included test data from all birds, each bird's responding to red light or tone was expressed as a ratio of the form $A /(A+C)$, where $A$ is the number of responses to the stimulus element and $C$ is the number of responses to the compound. Such a ratio has a value of .5 when the bird responds as often to the element as to the compound, and a value less than .5 if it responds less to the element than to the compound. Such a transformation effectively equates birds on test responding to the compound stimulus.

An analysis of variance (using Rodger's, 1974, 1975, method) of number of responses to tone/ (number of responses to tone + number of responses to compound) revealed significant differences among groups $[F(3,20)=3.87]$. Further analyses revealed no significant differences on this measure among Groups LC, LT, and CC. These three groups, taken together, showed a significantly higher ratio than did Group LL $(F=2.40)$. This analysis indicates, as did our earlier analysis, that there was no blocking of auditory control as a result of prior conditioning to red light.

An analysis of variance of number of responses to red light/ (number of responses to red light + number of responses to compound) also revealed significant differences among groups $[F(3,20)=3.77]$. Further analyses indicated no significant difference between Groups LL and LT. The ratio for Groups $L L$ and LT, taken together, was significantly higher than that for Group CC $(F=3.14)$. Finally, the ratio for Group LC did not differ from the ratio for Groups LL, LT, and CC taken together. This decision set implies that the ratio for Group LC is intermediate between that for Group $\mathrm{CC}$ and those for Groups $\mathrm{LL}$ and $\mathrm{LT}$ :

$$
\mathrm{CC}<\mathrm{LC}<\mathrm{LL}
$$

This analysis is in agreement with our earlier analysis in showing that Group LL was more responsive to red light than was Group CC. That is, tone overshadowed light in compound training. However, this analysis is discrepant with our earlier analysis in showing that, in Group LC, there was some loss in 
stimulus control by the light as a result of compound training.

\section{Discussion}

As in Experiment 2, there was no evidence that conditioning to a relevant stimulus-in this case, the tone-was blocked by prior conditioning to a less relevant stimulus-in this case, the red light. Furthermore, the conservative analysis that omitted data from two anomalous birds supports Experiment 2 in suggesting that the previously conditioned, less relevant stimulus did not lose control of responding when it was compounded with the relevant stimulus.

\section{GENERAL DISCUSSION}

Data from the compound training groups of Experiments 2 and 3 indicate that the stimulus-reinforcer interaction reported by Foree and LoLordo (1973) is maintained despite extensive overtraining. Visual dominance was observed following appetitive training, whereas auditory dominance was observed following avoidance training. Moreover, comparisons of test responding to tone in Groups TT and CC of Experiment 2, and of test responding to red light in Groups LL and CC of Experiment 3 indicate that light overshadows tone in appetitive training and that tone overshadows light in avoidance training. Third, the relative rates of acquisition of single-cue groups in Experiment 1 support Kamin's account of stimulus dominance in compound conditioning; that is, the dominant stimulus following compound conditioning was the stimulus that yielded faster acquisition in single-cue conditioning. The last result has also been obtained in a Pavlovian conditioning procedure, using the same stimuli (Shapiro, Jacobs, \& LoLordo, 1980).

The major findings of Experiments 2 and 3 arise from comparisons among Groups TC, TL, and TT of Experiment 2 and among Groups LC, LT, and LL of Experiment 3. The results of these comparisons can best be described as follows: When a highly relevant stimulus is added to an already conditioned, but less relevant, stimulus and reinforcement is available as before, then control by the relevant stimulus is not blocked. Moreover, there is little evidence for a decrease in stimulus control by the less relevant stimulus.

The test data have several implications for recent models of selective stimulus control. Although these models have focused on classical conditioning, they can readily be applied to the discrete-trials operant procedure used here. One such model that has aroused considerable interest was formulated by Rescorla and Wagner (1972; Wagner and Rescorla, 1972). According to this model of classical conditioning, the change in the associative strength of stimulus $A\left(\Delta V_{A}\right)$ as a result of a reinforced trial depends upon: (1) the difference between the maximum associative strength obtainable with the reinforcer $(\lambda)$ and the sum of the associative strengths of all stimuli present on the trial; (2) $\alpha_{A}$, a learning rate parameter for stimulus A; and (3) $\beta$, a learning rate parameter for the reinforcer. Bounded by 0 and $1, \alpha_{A}$ represents the salience of $A$, and $\beta$ represents the effectiveness of the reinforcer. When two stimuli, A and B, are present on a trial, Equation 1 describes the change in the associative strength of $B$ as a result of the trial:

$$
\Delta \mathrm{V}_{\mathrm{B}}=\alpha_{\mathrm{B}} \beta\left[\lambda-\left(\mathrm{V}_{\mathrm{A}}+\mathrm{V}_{\mathrm{B}}\right)\right] .
$$

The Rescorla-Wagner model accounts for blocking of conditioning to an added stimulus $B$ as a result of prior asymptotic conditioning to stimulus $A$ by noting that such a procedure makes $\mathrm{V}_{A}=\lambda$, implying that (since $V_{B}=0$ ) the quantity within parentheses in Equation 1 should equal zero, and that $\Delta V_{B}$ should equal zero, regardless of the value of $\alpha_{B}$. Less than complete blocking should occur if $\mathrm{v}_{\mathrm{A}}<\lambda$ at the beginning of compound conditioning, but so long as there is a high level of conditioning to $\mathrm{A}$, blocking should be detected. In Experiment 2, birds in Group TC responded on means of $78 \%, 73 \%, 64 \%, 75 \%$, and $78 \%$ of the presentations of tone on the last days of Phase 1, suggesting that the level of conditioning was asymptotic. Furthermore, Group TT, which continued to receive conditioning to tone in Phase 2, showed no consistent trend in the level of responding during that phase. Thus, it seems that, for Group TC, $\mathrm{V}_{\mathrm{T}}$ was asymptotic when light was added. Yet there was no demonstrable blocking of visual control. Thus, the Rescorla-Wagner model does not predict the failure of prior conditioning of a less relevant stimulus to block conditioning of a response to an added, but relevant, stimulus, even if the model makes the assumption that $\alpha_{\mathrm{L}}>\alpha_{\mathrm{T}}$, which it must do to predict the observed overshadowing of tone by light in Experiment 2. A comparable analysis of the data of Experiment 3 supports the same conclusion.

Rescorla (1978) has recently discussed a generalization of the Rescorla-Wagner model in which the asymptotic associative strength, $\lambda$, varies directly with the number of stimuli present on a trial. When applied to the blocking paradigm, the generalized model predicts that the addition of a highly salient stimulus to an already conditioned stimulus should increase the total value of $\lambda$, with the magnitude of the increase dependent upon the particular summation rule for $\lambda s$. Thus both the previously conditioned and the added stimulus should gain associative strength during compound conditioning (see Equation 1). Consequently, the generalized model correctly predicts less than complete blocking of conditioning to the added light in Group TC of Experiment 2. However, the model also predicts: (1) a higher level of test responding to tone in Group TC than in Group TT; and (2) in Group TC, increased probability of responding on compound training trials in Phase 2, 
compared with the probability of responding to tone in Phase 1. There was no evidence supporting either prediction. The data of Experiment 3 also provide some evidence against this model, disconfirming the first of the two predictions, though tending to confirm the second.

Mackintosh (1975) has provided another theoretical account of blocking (see also Moore \& Stickney, 1980, and Pearce and Hall, 1980). It relies on changes in stimulus salience, rather than on a fixed amount of associative strength to be apportioned among stimuli, to explain blocking. Consider an experiment in which there has been some conditioning to stimulus A, and then a novel stimulus B is added, with reinforcement unchanged. In this example, assume that the initial salience, or learning rate parameter, of $\mathbf{A}\left(\alpha_{A}\right)$ is somewhat smaller than that of $\mathbf{B}\left(\alpha_{B}\right)$. Mackintosh suggests that the changes in the salience or learning rate parameter of each stimulus $\left(\alpha_{A}\right.$ and $\left.\alpha_{B}\right)$ are described by the following rules:

$$
\begin{aligned}
& \Delta \alpha_{A} \text { is positive if }\left|\lambda-V_{A}\right|<\left|\lambda-V_{B}\right| \\
& \Delta \alpha_{B} \text { is positive if }\left|\lambda-V_{B}\right|<\left|\lambda-V_{A}\right| \\
& \Delta \alpha_{A} \text { is negative if }\left|\lambda-V_{A}\right| \geqslant\left|\lambda-V_{B}\right| \\
& \Delta \alpha_{B} \text { is negative if }\left|\lambda-V_{B}\right| \geqslant\left|\lambda-V_{A}\right|,
\end{aligned}
$$

where $V, \alpha$, and $\lambda$ are defined as in the RescorlaWagner model.

According to this model, $\left|\lambda-V_{A}\right|<\left|\lambda-V_{\text {context }}\right|$ during conditioning of $\mathrm{A}$, because background cues are not reliably followed by reinforcement. Thus, $\alpha_{A}$ should grow throughout Phase 1 of conditioning, and may be quite large by the start of Phase 2 . On the first compound conditioning trial, the novel CS $B$ should gain associative strength just as it would have if $A$ had not accompanied it. Because $\left|\lambda-V_{B}\right|$ $>\left|\lambda-V_{A}\right|$, by Equation $3 \alpha_{B}$ should decrease as a result of this trial, and should decrease further on the remaining compound trials. Because $\alpha_{B}$ declines steadily, $V_{B}$ should grow quite slowly after the first compound trial. Any demonstration of blocking requires a comparison between the experimental group and an appropriate control, for example, a group that receives only $A B$ trials. In the latter group, since $\alpha_{\mathrm{A}}$ is initially smaller than $\alpha_{\mathrm{B}}, \mathrm{CS} \mathrm{B}$ should gain more associative strength than $\mathrm{CS} A$ on the first (compound) trial. Thus, $\left|\lambda-\mathrm{V}_{\mathrm{B}}\right|<\left|\lambda-\mathrm{V}_{\mathrm{A}}\right|$ on Trial 2, and $\alpha_{B}$ will increase, whereas $\alpha_{A}$ will decrease. Thus, when the number of compound trials is equated, $V_{B}$ should be smaller in the blocking group than in the overshadowing control.

When Mackintosh's (1975) model is applied to the present Experiments 2 and 3, it erroneously predicts that there should be some blocking of conditioning to the added but relevant stimulus as a result of prior conditioning to the less relevant one. There was no evidence of blocking in either experiment (see Feldman, 1975, for an apparently related result).

Hall, Mackintosh, Goodall, and dal Martello (1977; Experiments 1 and 2) reported findings similar to those of the present Experiments 2 and 3. Moreover, in Experiment 3, they found that even when conditioning of a less salient stimulus produced some blocking of conditioning to an added, more salient stimulus, the less salient stimulus appeared to lose some stimulus control as a result of compound conditioning. In contrast, we have found that, in Experiment 2 and according to one analysis of Experiment 3, the first stimulus (relevant, and "less salient" in the terms of Hall et al.) retained its control of behavior despite extensive compound training, even though it did not block conditioning to the added, relevant (more salient) stimulus.

Hall et al. (1977) attempted to explain both the loss of control by stimulus $A$ and the failure of blocking in terms of Mackintosh's (1975) model. Their explanation relies on the assumption that at some point during compound conditioning $\left|\lambda-\mathrm{V}_{\mathbf{A}}\right|$ must be greater than $\left|\lambda-V_{B}\right|$. Otherwise, (1) $\alpha_{A}$ will never decline and $A$ will never lose control of responding, and (2) $\alpha_{B}$ will be driven toward zero, and blocking will be observed. For $\left|\lambda-V_{A}\right|>\left|\lambda-V_{B}\right|$, not only must the initial value of $\alpha_{B}$ exceed the maximum value reached by $\alpha_{A}$, but the associative strength of $A\left(V_{A}\right)$ must be considerably less than $\lambda$ at the end of Phase 1. The latter condition was not satisfied in Experiment 3 of Hall et al., because a control group that was conditioned to CS A (tone) in both Phases 1 and 2 had mean suppression ratios of .22 and .27 , respectively, at the end of these two 10-day treatments. Thus, conditioning to A (tone) must have been asymptotic at the end of Phase 1 . Conditioning also was asymptotic at the end of Phase 1 of the present experiments, thus $\left|\lambda-V_{A}\right|$ could never have exceeded $\left|\lambda-V_{B}\right|$, and at least some blocking should have been observed.

Thus, Mackintosh's model requires some modification to explain the present data. One modification might begin by stating that a highly relevant stimulus cannot be ignored, that is, that its $\alpha$ is large and cannot (in the limiting case) diminish. Given extensive compound training, $V_{B}$ will then be equal in a blocking group and an overshadowing control. This assumption can be relaxed so that $\alpha$ for a highly relevant stimulus can decline slowly, and Mackintosh's model will still predict our result if there has been extensive compound training. These considerations suggest a model in which the value of $\Delta \alpha$ is a function of the initial value of $\alpha$ for that stimulus, so that a high initial value of $\alpha$ leads to rapid increases in $\alpha$ when the stimulus is the best predictor, but slow decreases when it is not. Conversely, for less relevant stimuli, a grows slowly, but decreases quickly. Such a notion allows one to base testable predictions about 
the outcomes of blocking, overshadowing, and other compound cue procedures using new stimuli on the relative rates of acquisition that have been observed when those stimuli have been paired with reinforcement in single-cue designs.

Finally, two disclaimers seem appropriate. First, we have defined relevance on the basis of an observed stimulus-reinforcer interaction. If the mechanisms of various stimulus-reinforcer interactions are different, then there is no reason to assume that all relevant stimuli will have the same effect on behavior in blocking paradigms (e.g., Gillan \& Domjan, 1977; Schindler \& Weiss, Note 1). Second, it is by no means certain that failure of blocking will be restricted to cases in which the added stimulus is relevant; for example, highly salient stimuli that have not been embedded in a stimulus-reinforcer interaction may be difficult to block (e.g., Hall et al., 1977).

\section{REFERENCE NOTE}

1. Schindler, C. W., \& Weiss, S. J. Blocking control by relevant stimuli. Paper presented at the meeting of the Eastern Psychological Association, Hartford, Connecticut, April 1980.

\section{REFERENCES}

Azrin, N. H. A technique for delivering shock to pigeons. Journal of the Experimental Analysis of Behavior, 1959, 2, 161-163.

Capretta, P. J. An experimental modification of food preferences in chickens. Journal of Comparative and Physiological Psychology, 1961, 54, 238-242.

Chase, S. Selectivity in multidimensional stimulus control. Journal of Comparative and Physiological Psychology, 1968, 66, 787-792.

Coughlin, R. C., JR. Inexpensive pubis electrodes for delivering shock to pigeons. Journal of the Experimental Analysis of Behavior, 1970, 13, 368.

Estes, W. K., \& Skinner, B. F. Some quantitative properties of anxiety. Journal of Experimental Psychology, 1941, 29, 390-400.

Feldman, J. M. Blocking as a function of added cue intensity. Animal Learning \& Behavior, 1975, 3, 98-102.

Foree, D. D., \& LoLordo, V. M. Attention in the pigeon: The differential effect of food getting vs. shock avoidance procedures. Journal of Comparative and Physiological Psychology, 1973, 85, 551-558.

Fonee, D. D., \& LoLondo, V. M. Stimulus-reinforcer interactions in the pigeon: The role of electric shock and the avoidance contingency. Journal of Experimental Psychology: Animal Behavior Processes, 1975, 1, 39-46.

Gill.an, D. J., \& DomJaN, M. Taste-aversion conditioning with expected versus unexpected drug treatment. Journal of Experimental Psychology: Animal Behavior Processes, 1977, 3, 297-309.

Hall, G., Mackintosh, N. J., Goodall, G., \& dal Martello, M. Loss of control by a less valid or less salient stimulus compounded with a better predictor of reinforcement. Learning and Motivation, 1977, 8, 145-158.

Johnson, D. F. Determiners of selective stimulus control in the pigeon. Journal of Comparative and Physiological Psychology, 1970, 70, 298-307.

KAMIN, L. J. Predictability, surprise, attention, and conditioning. In B. A. Campbell \& R. M. Church (Eds.), Punishment and aversive behavior. New York: Appleton-Century-Crofts, 1969.

LoLondo, V. M. Selective associations. In A. Dickinson \& R. A. Boakes (Eds.), Mechanisms of learning and motivation: $A$ memorial to Jerzy Konorski. Hillsdale, N.J: Erlbaum, 1979.

Mackintosh, N. J. A theory of attention: Variations in associability of stimuli with reinforcement. Psychological Review, 1975, 82, 276-298.
Mackintosh, N. J., \& Honig, W. K. Blocking and enhancement of stimulus controls in pigeons. Journal of Comparative and Physiological Psychology, 1970, 73, 78-85.

Marchant, H. G., III, \& Moore, J. W. Blocking of the rabbit's conditioned nictitating membrane response in Kamin's twostage paradigm. Journal of Experimental Psychology, 1973, 101, 155-158.

Miles, C. G. Blocking the acquisition of control by an auditory stimulus with pretraining on brightness. Psychonomic Science, $1970,19,133-134$.

Moone, J. W., \& Stickney, K. J. Formation of attentionalassociative networks in real time: Role of the hippocampus and implications for conditioning. Physiological Psychology, 1980, 8, 207-217.

Pearce, J. M., \& Hall, G. A model for Pavlovian learning: Variations in the effectiveness of conditioned but not of unconditioned stimuli. Psychological Review, 1980, 87, 532-552.

Rescorla, R. A. Some comments on a model of conditioning. In J. Baerwaldt \& G. McCain (Eds.,), Recent developments in learning theory: The Arlington symposium. Stamford, Conn: Greylock Press, 1978.

Rescorla, R. A., \& WAgner, A. R. A theory of Pavlovian conditioning: Variations in the effectiveness of reinforcement and non-reinforcement. In A. H. Black \& W. F. Prokasy (Eds.), Classical conditioning II: Current research and theory. New York: Appleton-Century-Crofts, 1972.

Rodger, R. S. Multiple contrasts, error rate, and power. British Journal of Mathematical and Statistical Psychology, 1974, 27, 179-198.

RODGER, R. S. The number of non-zero, post-hoc contrasts from ANOVA and error rate. British Journal of Mathematical and Statistical Psychology, 1975, 28, 71-78.

Seligman, M. E. P. On the generality of the laws of learning. Psychological Review, 1970, 77, 406-418.

Seraganian, P., \& vom SaAl, W. Blocking the development of stimulus control when stimuli indicate periods of non-reinforcement. Journal of the Experimental Analysis of Behavior, 1969, 12, 767-772.

Shapiro, K. L., Jacobs, W. J., \& LoLordo, V. M. Stimulusreinforcer interactions in Pavlovian conditioning of pigeons: Implications of selective associations. Animal Learning \& Behavior, 1980, 8, 586-594.

Shettle worth, S. J. Constraints on learning. In D. S. Lehrman, R. A. Hinde, \& E. Shaw (Eds.), Advances in the study of behavior IV. New York: Academic Press, 1972.

ShetTleworth, S. J. "Constraints on conditioning" in the writings of Konorski. In A. Dickinson \& R. A. Boakes (Eds.), Mechanisms of learning and motivation: A memorial to Jerzy Konorski. Hillsdale, N. J: Erlbaum, 1979.

Suiter, R. D., \& LoLondo, V. M. Blocking of inhibitory Pavlovian conditioning in the conditioned emotional response. Journal of Comparative and Physiological Psychology, 1971, 76, 137-144.

Tennant, W. A., \& Bitterman, M. E. Blocking and overshadowing in two species of fish. Journal of Experimental Psychology: Animal Behavior Processes, 1975, 1, 22-29.

Trapasso, T., \& Bowe R, G. H. Attention in learning theory and research. New York: Wiley, 1968.

vom SaAl, W., \& Jenkins, H. M. Blocking the development of stimulus control. Learning and Motivation, 1970, 1, 52-64.

WAgner, A. R., \& Rescorla, R. A. Inhibition in Pavlovian conditioning: Application of a theory. In R. A. Boakes \& M. S. Halliday (Eds.), Inhibition and learning. London: Academic Press, 1972.

Willner, J. A. Blocking of a taste aversion by prior pairings of exteroceptive stimuli with illness. Learning and Motivation, $1978,9,125-140$.

(Manuscript received July 16, 1980; revision accepted for publication December 10, 1981.) 